\title{
Oxyfunctionalization of Nonnatural Targets by Dioxiranes. Selective Oxidation of Centropolyindans ${ }^{\perp}$
}

\author{
Dietmar Kuck, ${ }^{, \dagger}{ }^{\dagger}$ Andreas Schuster, ${ }^{\dagger}$ Caterina Fusco, $, \$, 8$ Michele Fiorentino, ${ }^{\ddagger}$ and \\ Ruggero Curci",*
}

Contribution from the Fakultät für Chemie, Universität Bielefeld, Universitätsstrasse 25, D-33501 Bielefeld, Germany, and the Centro C.N.R. "M.I.S.O.", Dipartimento Chimica, Università di Bari, v. Amendola 173, I-70126, Italy

Received August 3, $1993^{\circ}$

\begin{abstract}
The oxyfunctionalization of four centropolyindans, i.e., triptindan (2), 1,1'-(o-phenylene)-2,2' -spirobiindan (3), 10-methyltribenzoquinacene (4), and fenestrindan (5) at the benzylic and/or benzhydrylic $\mathrm{C}-\mathrm{H}$ bonds of their rigid polycyclic framework has been achieved using dimethyldioxirane 1a and methyl(trifluoromethyl)dioxirane $1 \mathrm{~b}$. The latter reagent was found to be considerably more effective than 1a, allowing both partial and complete oxyfunctionalization of the substrates examined. The rigidity of the polycyclic framework and steric factors in 2-5 seem to moderate the reactivity and selectivity of the dioxiranes with respect to $\mathrm{O}$-insertion into benzhydrylic vs benzylic $\mathrm{C}-\mathrm{H}$ bonds; for instance in the oxyfunctionalization of the angular centrotriindan 3 , the secondary benzylic alcohol 12 and the corresponding ketone 10 are obtained, along with the isomeric tertiary alcohol 11. The potentiality of $\mathbf{1 b}$ in effecting multiple oxygen insertion into $\mathrm{C}-\mathrm{H}$ bonds under quite mild conditions was demonstrated by the remarkable high yield 4-fold hydroxylation of fenestrindan (5) at the bridgehead positions. The results are interpreted in terms of an essentially concerted O-insertion by the dioxirane into the $\mathrm{C}-\mathrm{H}$ bonds encompassed in the rigid framework of the substrates. Adoption of an FMO model, which envisages dioxirane attack along the $\mathrm{O}-\mathrm{O}$ bond axis toward the carbon atom of the given $\mathrm{C}-\mathrm{H}$ bonds, provides a rationale for the reactivities and selectivities recorded.
\end{abstract}

\section{Introduction}

In recent years, the availability of dimethyldioxirane (1a) and of methyl(trifluoromethyl)dioxirane $\mathbf{1 b}$, the smallest ring peroxides containing carbon, ${ }^{1}$ in the isolated ${ }^{2}$ as well as in the in situ form, ${ }^{3}$ has led to extensive utilization of these powerful oxidants in a variety of synthetically useful transformations. ${ }^{1}$ Among these, a remarkable one is the efficient oxyfunctionalization of simple, "nonactivated" aliphatic $\mathrm{C}-\mathrm{H}$ bonds, ${ }^{4}$ for which $\mathbf{1 b}$ appears to be best suited. As an example, the hydroxylation of adamantane by 1 b occurs selectively at the bridgehead $\mathrm{C}-\mathrm{H}$ bonds under extremely mild conditions to afford 1,3,5-trihydroxy- and 1,3,5,7tetrahydroxyadamantane. ${ }^{4 b}$

Investigations concerning functional group selectivities attainable by using $1 \mathrm{a}$ and $\mathbf{1 b}$ are being actively pursued, ${ }^{5}$ and the oxyfunctionalization of natura $l^{6}$ as well as nonnatural ${ }^{7}$ target molecules is being explored. ${ }^{8}$

\footnotetext{
Universität Bielefeld, Germany.

₹ Universita di Bari , Italy.

In partial fulfillment of the requirements for the Ph.D. Degree.

$\perp$ The authors wish to dedicate this article to professor Giorgio Modena (University of Padova, Italy) on the occasion of his 70th birthday.

- Abstract published in Advance ACS Abstracts, February 15, 1994

(1) For reviews, see: (a) Curci, R. In Advances in Oxygenated Processes; Baumstark, A. L., Ed.; JAI: Greenwich, CT, 1990; Vol. 2, Chapter 1. (b) Adam, W.; Curci, R.; Edwards, J. O. Acc. Chem. Res. 1989, 22, 205. (c) Murray, R. W. Chem Rev. 1989, 89, 1187.

(2) (a) Murray, R. W.; Jeyaraman, R. J. Org. Chem. 1985, 50, 2847. (b) Cassidei, L.; Fiorentino, M.; Mello, R.; Sciacovelli, O.; Curci, R. J. Org. Chem. 1987, 52, 699. (c) Mello, R.; Fiorentino, M.; Sciacovelli, O.; Curci, R. J. Org. Chem. 1988, 53, 3890 .

(3) (a) Curci, R. Fiorentino, M. Troisi, L.; Edwards, J. O.: Pater, R. H J. Org. Chem. 1980, 45, 4758. (b) Curci, R.; Fiorentino, M.; Serio, M. R. J. Chem. Soc., Chem. Commun. 1984, 155.

(4) (a) Mello, R.; Fiorentino, M.; Fusco, C.; Curci, R. J. Am. Chem. Soc 1989, 111, 6749. (b) Mello, R.; Cassidei, L.; Fiorentino, M.; Fusco, C.; Curci R. Tetrahedron Lett. 1990, 31, 3067. (c) Murray, R. W.; Jeyaraman, R.; Mohan, L. J. Am. Chem. Soc. 1986, 108, 2470.

(5) For an overview of applications in synthesis, see: Adam W.; Hadjiarapoglou, L. P.; Curci, R.; Mello, R. In Organic Peroxides; Ando, W., Ed. Wiley, New York, 1992; Chapter 4, pp 195-219. See also references quoted therein.
}

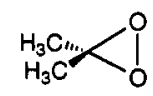

1a

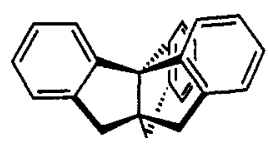

2

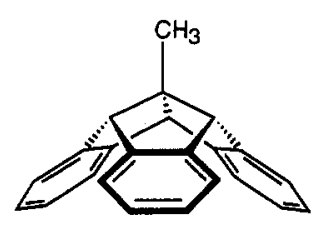

4

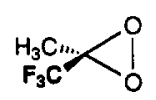

$1 \mathbf{b}$

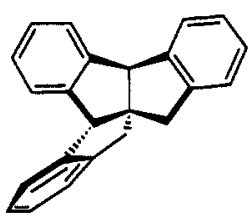

3

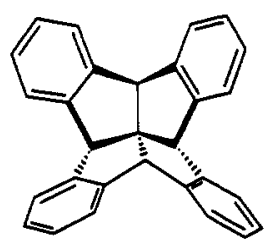

5
We have now turned to the oxidation of complex polycyclic hydrocarbons containing multiply fused indan units, i.e., the centropolyindans. ${ }^{9}$ These target molecules represent alkylbenzene moieties encompassed into a sterically rigid framework.

(6) For instance, see: (a) Cicala, G.; Curci, R.; Fiorentino, M.; Laricchiuta, O. J. Org. Chem. 1982, 47, 2670 (b) Baertschi, S. W.; Raney, K. D.; Stone, M. P.; Harris, T. M. J. Am. Chem. Soc. 1988, 110, 7929. (c) Chow, K.; Danishefsky, S. J. J. Org. Chem. 1990, 55, 4211. (d) Marples, B. A. Muxworthy, J. P.; Baggaley, K. H. Tetrahedron Lett. 1991, 32, 533. (e) Bovicelli, P.; Lupattelli, P.; Mincione, E.; Prencipe, T.; Curci, R. J. Org. Chem. 1992, 57, 2182, 5052. (f) Lluch, A.-M.; Sanchez-Baeza, F.; Messeguer, A.; Fusco, C.; Curci, R. Tetrahedron 1993, 49, 6299.

(7) Seebach, D. Angew. Chem., Int. Ed. Engl. 1990, 29, 1320.

(8) For instance, see: (a) Pramod, K.; Eaton, P. E.; Gilardi, R.; FlippenAnderson, J. L. J. Org. Chem. 1990, 55, 6105. (b) Elemes, Y.; Silverman, S. K.; Sheu, C.; Kao, M.; Foote, C. S.; Alvarez, M. M.; Whetten, R. L. Angew. Chem., Int. Ed. Engl. 1992, 31, 351. (c) Teager, D. S.; Murray, R. K., Jr. J. Org. Chem. $1993,58,5549$.

(9) (a) Kuck, D. In Quasicrystals, Networks, and Molecules of Fivefold Symmetry; Hargittai, I., Ed.; VCH: New York, 1990; Chapter 19. (b) Kuck, D.: Seifert, M. Chem. Ber. 1992, 125, 1461. (c) Kuck, D.; Schuster, A. Angew. Chem., Int. Ed. Engl. 1988, 27, 1192. (d) Kuck, D.; Schuster, A.: Ohlhorst, B.; Sinnwell, V.; de Meijere, A. Angew. Chem., Int. Ed. Engl. 1989, $28,595$. 
Scheme 1

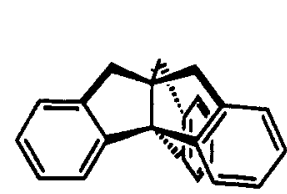

2

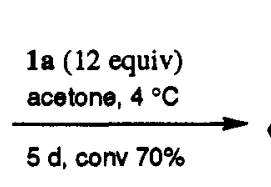

$5 \mathrm{~d}$, conv $70 \%$

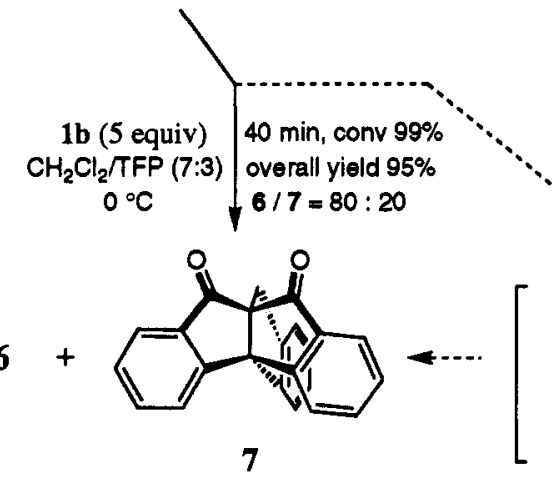

7

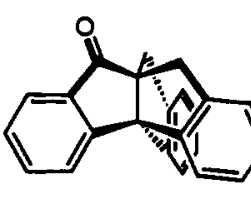

$6(37 \%)$

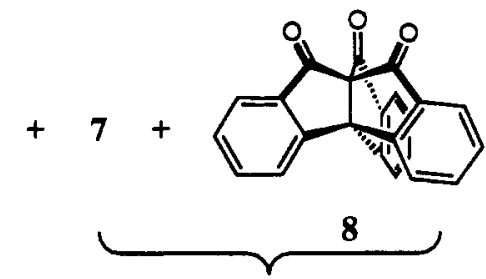

not isolated
All of the available evidence indicate a nonradical, "oxenoid" mechanism for the O-atom insertion by the dioxiranes into the unactivated $\mathrm{C}-\mathrm{H}$ bond of hydrocarbons. In line with a mechanism developing neither marked radical nor carbenium ion character, kinetics and competition experiments show that $\mathrm{O}$-insertion by dioxiranes into benzylic or benzhydrylic $\mathrm{C}-\mathrm{H}$ is of no particular advantage over insertion into alkane or cycloalkane $\mathrm{C}-\mathrm{H}$ bonds. ${ }^{4}$ Actually, it has been pointed out that dioxirane oxidations are more sensitive to steric (and stereoelectronic) demands than to electronic effects. 1,4a,5,6e For simple alkylbenzenes, the selectivity in the oxyfunctionalization at the cumene $\mathrm{PhMe}_{2} \mathrm{C}-\mathrm{H}$ vs ethylbenzene $\mathrm{PhMeCH}-\mathrm{H}$ is ca. $4: 2$ for dioxirane $1 \mathrm{a}^{4 \mathrm{c}}$ and $\mathrm{ca}$. 3:2 for the more reactive dioxirane $1 \mathrm{~b} ;{ }^{4 a}$ thus, the $R_{\mathrm{s}}^{\mathrm{t}}$ value (i.e., the tertiary vs secondary selectivity factor, after statistical correction) is ca. 4 and 3 , respectively. This is much lower than the $\boldsymbol{R}_{\mathrm{s}}^{\mathrm{t}}$ values normally recorded for cyclic, polycyclic, or open chain alkanes. ${ }^{4 a}$

With this background, it appeared interesting to us to investigate into the selectivities attainable using dioxiranes for the oxyfunctionalization of centropolyindans 2-5, since these hydrocarbon substrates bear benzylic methylene and/or benzhydrylic methine $\mathrm{C}-\mathrm{H}$ bonds in sterically exposed or shielded positions, encompassed in a rigid framework. ${ }^{10}$ We report herein that both dioxiranes $1 \mathrm{a}$ and $1 \mathrm{~b}$ can be successfully employed to achieve either a single or the multiple oxyfunctionalization of triptindan (2), ${ }^{11,12} 1,1^{\prime}$ (o-phenylene)-2,2'-spirobiindan (3), 13a,14 10-methyltribenzotriquinacene (4), ${ }^{13 a, 15}$ and fenestrindan (5). ${ }^{13 b, 14}$

\section{Results and Discussion}

Oxidation of Triptindan (2). This propellane-type hydrocarbon was reacted with 11 molar excess of $0.15 \mathrm{M} 1 \mathrm{a}$ in acetone at room temperature. After 4 days, the reaction mixture contained, besides some starting material, 9-triptindanone (6) as the major product (Scheme 1). Column chromatography furnished pure 6 in $27 \%$ yield as well as ca. $30 \%$ of recovered 2 . The monoketone 6 thus

(10) Concerning the concave and convex "surfaces" and the limited conformational flexibility of the centropolyindans, see: (a) Ceccon, A.; Gambaro, A.; Manoli, F.; Venzo, A.; Kuck, D.; Bitterwolf, T. E.; Ganis, P.; Valle, G. J. Chem. Soc., Perkin Trans. II 1991, 233. (b) Paisdor, B.; Grützmacher, H.-F.; Kuck, D. Chem. Ber. 1988, 121, 1307. (c) Ceccon, A.; Gambaro, A.; Manoli, F.; Venzo, A.; Ganis, P.; Valle, G.; Kuck, D. Chem. Ber. 1993, $126,2053$.

(11) Paisdor, B.; Kuck, D. J. Org. Chem. 1991, 56, 4753.

(12) (a) Thompson, H. W. J. Org. Chem. 1968, 33, 621. (b) Thompson, H. W. Tetrahedron Lett. 1966, 6489.

(13) (a) Kuck, D. Angew. Chem., Int. Ed. Engl. 1984, 23, 508. (b) Kuck, D.; Bogge, H. J. Am. Chem. Soc. 1986, 108, 8107.

(14) Kuck, D. Chem. Ber, 1994, 127, 409.

(15) Kuck, D.; Lindenthal, T.; Schuster, A. Chem. Ber. 1992, 125, 1449. obtained was isolated and fully characterized (see Experimental Section); it proved to be identical with the material obtained by independent synthesis. ${ }^{11}$ The formation of sizable amounts of more highly oxidized products - such as 9,10-triptindandione (7), 9,10,11-triptindantrione (8), ${ }^{11}$ and the corresponding ketols-was detected by mass spectrometry. However, separation of all oxidation products was not achieved.

The more reactive $2 c, 4,6 e$ dioxirane 1 b gave similar results, but reaction times were much shorter. In fact, reaction of 2 with 5 equiv of $1 \mathrm{~b}$ in $\mathrm{CH}_{2} \mathrm{Cl}_{2}$ at $0^{\circ} \mathrm{C}$ led to practically total conversion of the substrate during only $40 \mathrm{~min}$, the monoketone 6 and the diketone 7 being produced in a 4:1 ratio (Scheme 1). The GC/ MS monitoring of the reaction revealed that 9,10-triptindandiol (9) (indicated by its strong $\left[\mathrm{M}-\mathrm{H}_{2} \mathrm{O}\right]^{++}$peak) ${ }^{16}$ is formed as an intermediate, being completely transformed into 7 by the end of the reaction.

Oxidation of $1,1^{\prime}$-(a-Phenylene)-2,2'-spirobiindan (3). This target, an isomer of triptindan 2, was reacted with both dioxiranes $1 \mathrm{a}$ and $1 \mathrm{~b}$. Oxidation of 3 with a 4 -fold excess of dimethyldioxirane 1a (eq 1) furnished, after 4 days at room temperature, the corresponding monoketone $\mathbf{1 0}$ and tertiary alcohol $\mathbf{1 1}$ in relatively low isolated yields ( $28 \%$ and $16 \%$, respectively). The overall conversion was rather low since ca. $37 \%$ of the starting

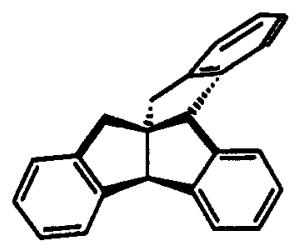

3

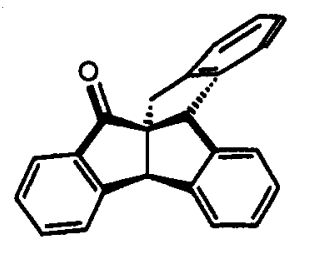

$10(28 \%)$
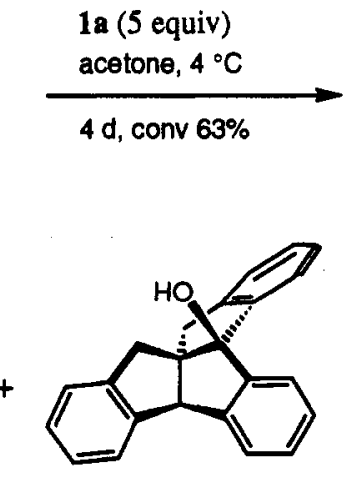

$11(16 \%)$ material could be recovered. Also, the formation of higher oxidation products was detected by MS.

(16) For stereoselective water eliminations from molecular ions, see: (a) A. Mandelbaum In Stereochemistry; Kagan, H. B., Ed.; Thieme: Stuttgart, FRG, 1977; Vol. 1, pp $137 f f$. (b) Grützmacher, H.-F.; Asche, R. Chem. Ber. 1975, 108, 2080. (c) Kuck, D.; Filges, U. Org. Mass Spectrom. 1988, 23, 643. (d) Kuck, D.; Neumann, E.; Schuster, A. Chem. Ber. 1994, I27, 151. 
The two major oxidation products were fully characterized. In fact, the mass spectrum of ketone 10 is dominated by the molecular ion peak, in contrast to that of the alcohol 11 which shows a strong $\left[\mathrm{M}-\mathrm{H}_{2} \mathrm{O}\right]^{++}$peak instead of the $\mathrm{M}^{++}$signal. This behavior can be reconciled with the exposed position of the labile hydroxyl group in 11.16 The structures of 10 and 11 were also established by their ${ }^{1} \mathrm{H}$ NMR spectra which show characteristic AB spin systems and singlets for the benzylic methylene and methine groups, respectively. ${ }^{17}$

Oxidation of 3 with methyl(trifluoromethyl)dioxirane 1 b occurs much more readily than with dimethyldioxirane 1a (eq 2). In these experiments, the reaction mixture was analyzed by $G C$ and the products identified after conversion into the corresponding acetates 11a and 12a. With a 1 molar excess of 1b, a $40 \%$ conversion of the substrate was achieved at $-20^{\circ} \mathrm{C}$ in only 2.5 $\mathrm{h}$; based on the amount of substrate consumed, the overall yield was $>98 \%$. Again, the monoketone 10 and the tertiary alcohol 11 were the main products (yields $39 \%$ and $38 \%$, respectively); however, the secondary alcohol 12 was also formed in sizable amounts (21\%). ${ }^{17}$

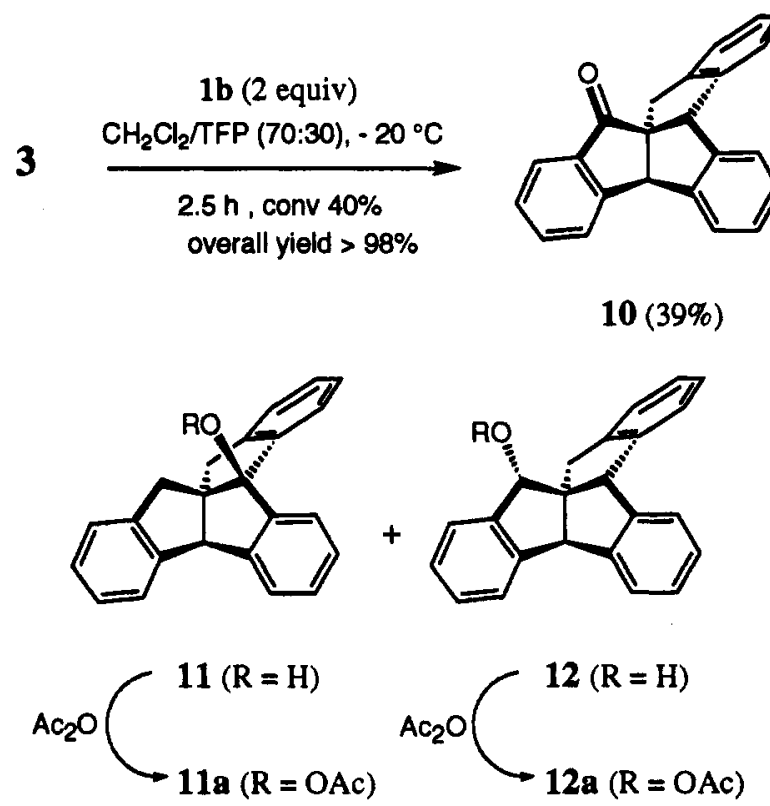

$(38 \%)$

(21\%)

The competing formation of the three products 10-12 from 3 is interesting. In fact, this centrotriindan, containing both benzylic and bridgehead benzhydrylic $\mathrm{C}-\mathrm{H}$ bonds, shows a preference for the oxyfunctionalization at the secondary benzylic positions over the tertiary $\mathrm{C}-\mathrm{H}$ bonds. As mentioned above, simple alkyl-

(17) Upon reduction ( $\mathrm{LiAlH}_{4}$ ) of ketone 10, alcohol 12' (stereoisomeric with 12) could be prepared independently, and its spectral characteristics compared with those of 11 (cf. Experimental Section). The endo ( $\alpha$ ) orientation of the 13-OH group in 12' follows from the observed distinct downfield shift (ca. $0.5 \mathrm{ppm}$ ) of the bridgehead proton $(4 \mathrm{~b}-\mathrm{H})$ resonance with respect to that of thestarting material 3, due to magnetic deshielding exercised by the hydroxy group. The stereochemistry of $12^{\prime}$ is confirmed by ' $\mathrm{H}-{ }^{1} \mathrm{H}$ NOESY measurements. Of course, a marked downfield shift of the $4 \mathrm{~b}-\mathrm{H}$ resonance would not be expected with an exo $(\beta) \mathrm{OH}$ (or OAc) group; in fact, close chemical shifts were recorded for the resonances of the $4 \mathrm{~b}$ and $8 \mathrm{~b}$ protons in the alcohol derivative 12a having a $13 \beta-O A c$ (exo) stereoorientation.

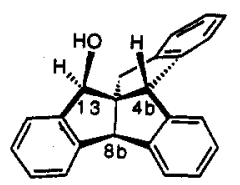

12 benzenes $4 a, c, 18$ exhibit selectivity in favor of tertiary over secondary benzylic C-H bonds (i.e., $R_{\mathrm{s}}^{\mathrm{t}}$. from 3 to 4 ). Also, oxidation of diphenylmethanes and fluorenes with $1 \mathrm{a}$ was found to be more efficient with tertiary than with secondary $\mathrm{C}-\mathrm{H}$ bonds. ${ }^{18}$ For the substrate at hand, a $R_{\mathrm{s}}$ value of ca. 1.2 is estimated; thus the tertiary over secondary selectivity practically fades away. Most likely, this is due to a greater steric hindrance at the bridgehead $\mathrm{C}-\mathrm{H}$ in reaching the optimal stereoalignment for O-insertion by the dioxirane (see below).

It is also worthy of note that $1 \mathrm{a}$ and $\mathbf{1 b}$ appear to display similar regioselectivities in the oxyfunctionalization of 3 . Indeed, with a large excess of 1a, the secondary alcohol 12 is completely reacted further to the ketone 10 , to give roughly a $2: 1$ selectivity (based on product yields) in favor of methylene group functionalization. With the more reactive reagent 1 b used in stoichiometric amounts (with respect to the ketone product), the secondary alcohol 12 survives, and the product selectivity is again in favor (ca. 3:2) of the methylene group oxidation.

Oxidation of 10-Methyltribenzotriquinacene (4). At variance with the centrotriindans a bove, the tribenzotriquinacene 4 contains only benzhydrylic $\mathrm{C}-\mathrm{H}$ bonds. As shown in eq 3, treatment of 4 with a large excess of dimethyldioxirane 1a during 5 days at room temperature resulted in efficient conversion $(95 \%)$ to the corresponding bridgehead alcohols 13-15 (MS analysis).
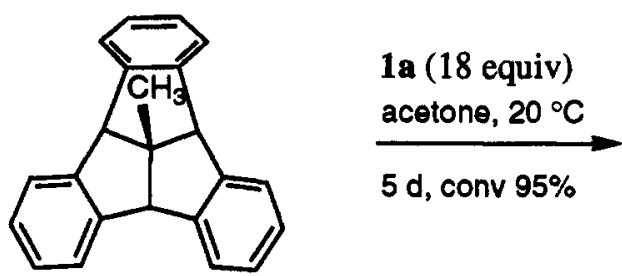

$5 d$, conv $95 \%$

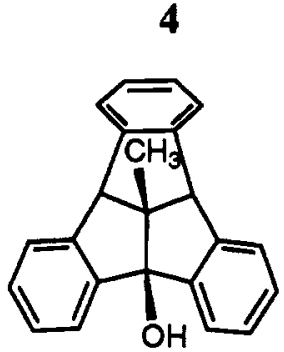

$13(10 \%)$

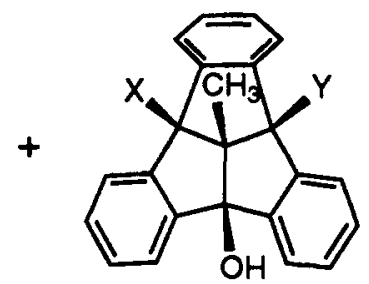

$14(X=O H, Y=H)$

$15(X=Y=O H)$

not isolated
Unfortunately, chromatographic separation of the higher alcohols 14 and 15 (representing an over $70 \%$ fraction of the crude product mixture) was unsuccessful, so that just monoalcohol 13 could be isolated albeit in low (10\%) yield. The comparison of MS and 'HNMR spectra of 13 with those of the same material obtained by independent synthesis unequivocally allowed its identification. ${ }^{19}$

Oxyfunctionalization of 4 was easy employing methyl(trifluoromethyl)dioxirane $\mathbf{1 b}$, so that it was carried out with both low and high relative amounts of the oxidant. Treatment of 4 with 1.8 equiv of $1 \mathrm{~b}$ at $-20^{\circ} \mathrm{C}$ during $40 \mathrm{~min}$ resulted (GC analysis) in $35 \%$ conversion to the monoalcohol $\mathbf{1 3}$ as the only reaction product (eq 4). The alcohol product was acetylated to give 13a, which in turn was identified by MS and ${ }^{1} \mathrm{H}$ NMR.

(18) Kuck, D.; Schuster, A. Z. Naturforsch. 1991, 46B, 1223

(19) (a) The mass spectra of bridgehead substituted tribenzotriquinacenes (such as 13) will be reported in a separated paper: Kuck, D.; Schuster, A., to be published. (b) The monoalcohol 13 as well as diol 14 and triol 15 were synthesized independently, cf.: Schuster, A. Doctoral Thesis, University of Bielefeld, 1991. Kuck, D.; Schuster, A., to be published. 

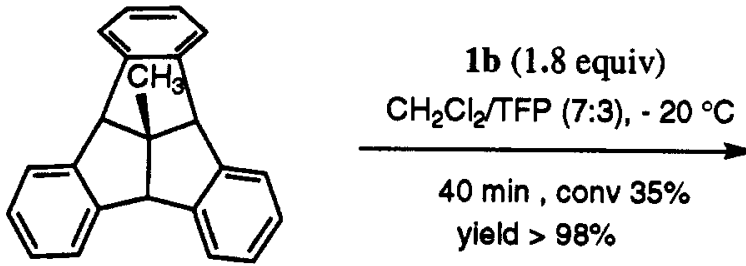

4
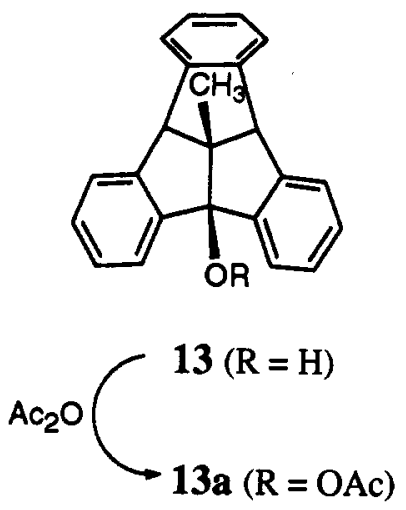

However, our attempts to generate diol 14 and triol 15 selectively upon reaction of this substrate with methyl(trifluoromethyl)dioxirane $1 \mathrm{~b}$ have failed so far. Indeed, treatment of 4 with a large excess of $1 \mathrm{~b}$ at a higher temperature $\left(0^{\circ} \mathrm{C}\right)$ seemingly resulted in oxidation of the methyl group to carboxyl, along with oxyfunctionalization at all three bridgehead $\mathrm{C}-\mathrm{H}$ bonds. This surprising result might be ascribed to the unique disposition of the central $\mathrm{CH}_{3}$ group in 4 , which is sterically exposed to attack by the powerful oxidant. According to NMR analysis, the conversion of 4 was remarkably efficient ( $>90 \%$, based on the disappearance of the $\mathrm{CH}_{3}$ resonance). Due to very poor solubility and volatility of the product(s) arising from this "exhaustive" oxidation of 4 , satisfactory separation and purification upon transformation into derivatives (e.g., acetates) has not been achieved yet, so that its full characterization is still pending. ${ }^{20}$

That the controlled reaction of 4 with excess $1 b$ would possibly bring about oxidation at the $\mathrm{CH}_{3}$ group is quite telling. In fact, assuming the crucial intermediate is triol $\mathbf{1 5}$ (which bears three polar hydroxy groups in a strictly syn-periplanar orientation with respect to the central methyl group), it hints at a case of oxygen atom insertion by stereochemical direction into a formally

(20) The data available so far point to the formation of 12d-carboxy-4a,8a,12a-trihydroxytribenzotriquinacene (16) as the major product. In fact, in an attempt to perform hydroxylation of all three bridgehead $\mathrm{C}-\mathrm{H}$, substrate $4(100 \mathrm{mg}, 340 \mathrm{mmol})$ in $\mathrm{CH}_{2} \mathrm{Cl}_{2}$ at $0^{\circ} \mathrm{C}$ was treated with a 4 -fold excess of dioxirane $1 \mathrm{~b}$ solution. The peroxide content was checked by iodometry and, after the dioxirane had been consumed, a further aliquot of oxidant was added. This procedure was repeated until an ca. 16-fold excess of 1a had been added during $36 \mathrm{~h}$. As the oxidation proceeded, formation of a light brown precipitate was noted. At the end of the reaction, removal of volatiles in vacuo afforded a brown residue [150 mg, mp $185-195^{\circ} \mathrm{C}$; IR $\left.(\mathrm{KBr}) 1719 \mathrm{~cm}^{-1}(\mathrm{C}=\mathrm{O})\right]$ trifluoroacetylation (trifluoroacetic anhydride/py) of the crude oxidation product gave (in low yield) a material exhibiting in its ${ }^{1} \mathrm{H}$ NMR spectrum (THF-d8) the pattern of degenerate $\mathbf{A A}^{\prime} \mathbf{B B}^{\prime}$ spin systems, which is typical of symmetrically substituted tribenzotriquinacenes. ${ }^{15}$ One of the two resonances was shifted downfield by ca. $\mathbf{0 . 6} \mathrm{ppm}$ as compared to the corresponding 10 metbyl trifluoroacetyl triester, ${ }^{196}$ and a new singlet line appeared at $\delta=13.3$ in place of the methyl resonance.

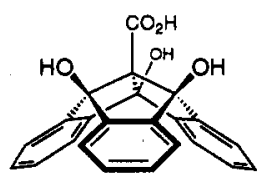

nonactivated methyl $\mathrm{C}-\mathrm{H}$ bond. To our knowledge, this has just one precedent in dioxirane chemistry. ${ }^{21}$ Further studies are underway in our laboratories on this unusual case.

Oxidation of Fenestrindan (5). Analogous to tribenzotriquinacene 4 , fenestrindan 5 contains only benzhydrylic $\mathrm{C}-\mathrm{H}$ bonds at the bridgehead positions. At variance to the former, however, all of these bonds point to concave sides of the two molecular "surfaces" of this centropolyindan. Therefore, steric hindrance was expected in the reaction of $1 \mathrm{a}$ and $\mathbf{1 b}$ with this target. However, its oxyfunctionalization by the dioxiranes presented no particular problem. In fact, by using an excess ( $>10$ equiv) of dimethyldioxirane 1a, MS monitoring revealed that 5 gives rise after 3 days at $0{ }^{\circ} \mathrm{C}$ to tetraol 18 as the major product, along with the corresponding di- and triols. The tetrol 18 could be isolated in low yield from the product mixture and proved to be identical to an authentic sample synthesized independently ${ }^{22 a}$ via the related tetrabromofenestrindan. ${ }^{22 b}$

The reaction of fenestrindan 5 with methyl(trifluoromethyl)dioxirane 1b, under both conditions of low and large excess oxidant, was more efficient (Scheme 2). In fact, by using just 1.5 equiv of $1 \mathrm{~b}, 56 \%$ conversion of the substrate could be achieved within only $25 \mathrm{~min}$ at $-10^{\circ} \mathrm{C}$ (HPLC monitoring).

The monoalcohol 17 was formed selectively in $>96 \%$ yield, as shown after acetylation to give the corresponding ester 17a. The identity of this derivative was evident from its ${ }^{1} \mathrm{H}$ and ${ }^{13} \mathrm{C}$ NMR spectra, both reflecting its formal $C_{s}$ symmetry. For instance, the presence of one distinct and two magnetically equivalent bridgehead methine groups is indicated by two singlets $(1: 2)$ in its ${ }^{1} \mathbf{H}$ NMR spectrum.

Then, by using a large excess ( 10 equiv) of $1 \mathrm{~b}$ under similar conditions, fenestrindan 5 could be oxidized almost quantitatively (97\%), giving rise to the corresponding tetraol 18 in $56 \%$ yield (as determined by HPLC, after conversion to the corresponding tetraacetate 18a). The high (formal) $D_{2 d}$ symmetry of 18a (cf., Scheme 2) was reflected from its ${ }^{1} \mathrm{H}$ NMR spectrum which showed only one resonance for the acetate groups and one $\mathrm{AA}^{\prime} \mathrm{BB}^{\prime}$ pattern for the arene protons. ${ }^{23}$ The same degeneracy was found with tetraol 18.22 Similar to the corresponding tetrakis(trifluoroacetate) of $18,{ }^{19 b}$ the solubility of $18 \mathrm{a}$ is quite low, so that the notoriously weak resonances originating from the central carbon (C-16d) and the quaternary arene carbon atoms are missing in its ${ }^{13} \mathrm{C}$ NMR spectrum.

Reaction Mechanism. Our results concerning oxyfunctionalization of the centropolyindans provide interesting insights into $\mathrm{O}$-insertions into $\mathrm{C}-\mathrm{H}$ bonds by dioxiranes. For instance, the reactivity of the benzhydrylic $\mathrm{C}-\mathrm{H}$ bonds of tribenzotriquinacene 4 and fenestrindan 5 toward dioxiranes appears to be enhanced with respect to that of nonrigid diphenylmethanes such as $\mathrm{Ph}_{2} \mathrm{C}$ (Me)-H and even of triphenylmethane $\mathrm{Ph}_{3} \mathrm{C}-\mathrm{H} .{ }^{18}$ This may be a consequence of the sterically exposed position of the bridgehead $\mathrm{C}-\mathrm{H}$ bonds in the rigid framework of the substrates at hand and to stereoelectronic requirements for $\mathrm{O}$-insertion.

Indeed, it has been pointed out that selectivities recorded in dioxirane oxidations of hydrocarbons cannot be interpreted in the simple terms of radical $\mathbf{H}$-abstraction reactions. Rather, an essentially concerted "oxenoid" $\mathrm{O}$-insertion into hydrocarbon $\mathrm{C}-\mathrm{H}$ bonds seems to be operative. $4 \mathrm{a}, \mathrm{b}, 6 \mathrm{6}, 8 \mathrm{c}$ Bach and co-workers ${ }^{24}$ have recently performed careful $a b$ initio calculations in support of a

(21) A parallel to our finding is the recently reported oxidation of a methyl group in a sterically hindered 3,3-dimethylcyclopropene: Maynard, G. D.; Paquette, L. A. J. Org. Chem. 1991, 56, 5480.

(22) (a) Kuck, D.; Schuster, A.; Krause, R. A. J. Org. Chem. 1991, 56, 3472. (b) Schuster, A.; Kuck, D. Angew. Chem., Int. Ed. Engl. 1991, 30, 1699 .

(23) It is interesting to note that the tetraacetate $18 \mathrm{n}$ shows fast interconversion of the two $S_{4}$ symmetrical ground-state conformers to give apparent $D_{2 d}$ molecular symmetry, akin to the tetraalcohol 18 itself, whereas the tetrakis(trifluoroacetate) of 18 behaves "static" on the NMR time scale.22

(24) Bach, R. D.; Andrés, J. L.; Owensby, A. L.; McDouall, J. J. W. J. Am. Chem. Soc. 1993, 115, 5768. We are indebted to Professor Bach for making his data available to us prior to publication and for helpful discussions. 
Scheme 2

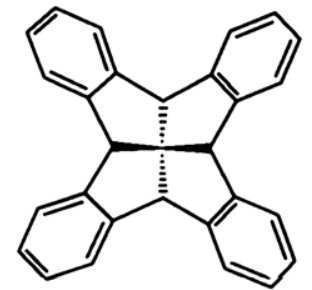

5

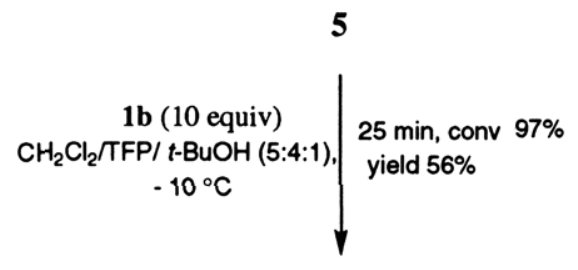

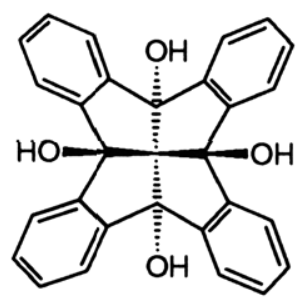

18
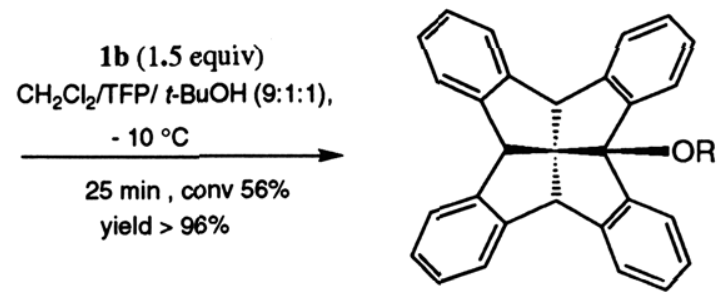

$A c_{2} O\left(\begin{array}{c}17(\mathrm{R}=\mathrm{H}) \\ 17 \mathbf{a}(\mathrm{R}=\mathrm{OAc})\end{array}\right.$ frontier MO theory that provides a unique rationale for both the stereospecificity and the stereoselectivity of $\mathrm{O}$-insertion into hydrocarbon $\mathrm{C}-\mathrm{H}$ bond by electrophiles and peroxides. In this FMO analysis, the electrophilic attack is directed along the peroxide $\mathrm{O}-\mathrm{O}$ bond axis toward the relevant carbon atom ${ }^{25}$ of the substrate, so that the dioxirane electrophilic oxygen approaches a filled C-H fragment orbital containing both a carbon 2 p orbital and a hydrogen atom. The latter is then favorably oriented to be shifted to the approaching oxygen atom, which employs an electron pair to serve as migration terminus, while the $\mathrm{O}-\mathrm{O}$ bond is being broken. For dimethyldioxirane attack at a generic tertiary $\mathrm{C}-\mathrm{H}$, this should produce a transition state (ts) geometry such as 19 (Chart 1); here we use the filled $\pi_{\mathrm{CHR}}$ fragment orbital of the hydrocarbon in justaposition with the dioxirane empty $\sigma^{*}$ o-o orbital, since Bach's calculations suggest that this produces a preferred orientation of approach. ${ }^{24}$

The application of this model of $\mathrm{O}$-insertion into the bridgehead C-H bonds of 10-methyltribenzotriquinacene and of fenestrindan is shown by $\mathbf{2 0}$ and 21, respectively (Chart 1); it can be seen that the given stereoalignment should produce fairly similar steric strain.

It has been mentioned above that dioxiranes normally display considerable selectivity in favor of oxyfunctionalization of methine over methylene groups, which is not observed for $1,1^{\prime}-(o-$ phenylene)-2,2'-spirobiindan (3). The decline of tertiary over secondary selectivity recorded for this angular centrotriindan most likely arises from steric hindrance to optimal stereoalignment at the encumbered concave molecular "surface" of the diindan subunits, ${ }^{10}$ as represented in ts 22 (Chart 1$)$.

Concerning polyoxyfunctionalization of all centropolyindans examined, the ease of further $\mathrm{O}$-atom insertion seems to increase as soon as a first $\mathrm{OH}$ functionality has been introduced; this could be tentatively ascribed to a cooperative effect exercised by the newly introduced hydroxy group, which-through hydrogen bonding in the ts-might facilitate attack by the dioxirane at a proximal C-H bond favorably oriented. This sort of cooperative

(25) A recently reported computational study at high level of theory also indicate that nitrosonium cation, a model electrophile, attacks methane at carbon rather than at a C-H bond.Schreiner, P. R.;Schleyer, P.v. R.;Schaefer, H. F. J. Am. Chem. Soc. 1993, 115, 9659.

\section{Chart 1}

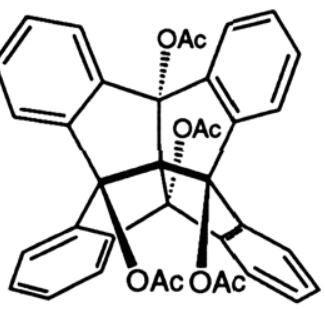

18a

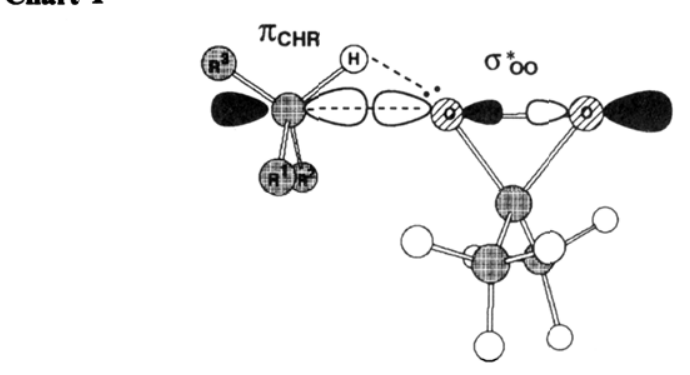

19

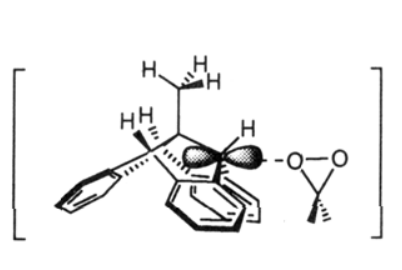

20

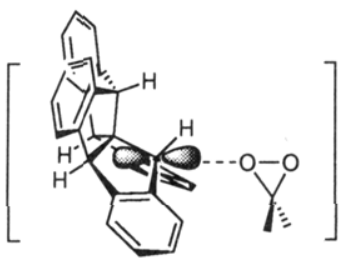

21

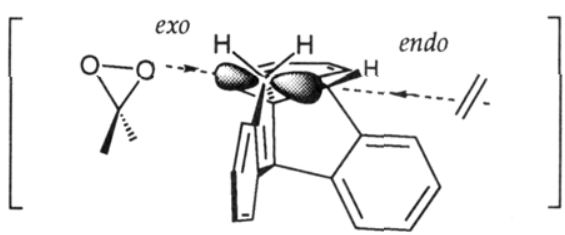

22

effect would have several precedents in selective oxidations by peroxides $^{26}$ and might contribute to the readily occuring remarkable 4-fold oxyfunctionalization of fenestrindan 5.

(26) (a) Dankleff, M. A. P.; Curci, R.; Edwards, J. O.; Pyun, H.-Y. J. Am Chem. Soc. 1968,90, 3209. (b) Curci, R.; Edwards, J. O. In Organic Peroxides; Swern, D., Ed.; Wiley-Interscience: New York, 1970; Vol. 1, Chapter IV. (c) Rebek, J.; Marshall, L.; Wolak, R.; McManis, J. J. Am. Chem. Soc. 1984, 106, 1170. (d) For an excellent discussion of the transition-state geometries in epoxidations, see: Finn, M. G.; Sharpless, K. B. In Asymmetric Synthesis; Morrison, J. D., Ed.; Academic: New York, 1985; Vol. 5, Chapter 8. 


\section{Conclusions}

Data presented herein demonstrate that oxyfunctionalization at the various benzylic and benzhydrylic $\mathrm{C}-\mathrm{H}$ bonds of centropolyindans can be cleanly performed using both dimethyldioxirane 1a and methyl(trifluoromethyl)dioxirane 1b. In line with previous work, $3 c, 4 a, b, 6 e$ the latter reagent is found to be considerably more effective than $1 \mathbf{a}$, so that both partial and complete oxyfunctionalization of the substrates can be achieved using the latter reagent. Therefore, the potentiality of dioxirane $1 \mathrm{~b}$ in performing multiple $\mathrm{O}$-insertions into $\mathrm{C}-\mathrm{H}$ bonds of complex target molecules such as the centropolyindans examined has been demonstrated. The rigidity of the polycyclic framework in 2-5, coupled to steric effects and stereoelectronic requirements, seem to dictate the reactivity and selectivity of the dioxiranes toward the benzylic and/or benzhydrylic $\mathrm{C}-\mathrm{H}$ bonds in the substrate. Our data suggest that the application of the aforementioned new model of $\mathrm{O}$-insertion by dioxirane into hydrocarbon $\mathrm{C}-\mathrm{H}$ bonds might offer a better understanding of selectivities recorded when dealing with complex and / or sterically congested molecules, such as the polyindans examined.

\section{Experimental Section}

Equipment. Boiling points and melting points (Bûchi 512 apparatus) were not corrected. The ${ }^{1} \mathrm{H}$ and ${ }^{13} \mathrm{C}$ NMR spectra were recorded on a Bruker AM 300 ( $\mathrm{J}$-modulated spin echo measurements) or a Varian XL 200 spectrometer. The ${ }^{1} \mathrm{H}$ NMR are referenced to residual isotopic impurity $\mathrm{CHCl}_{3}$ (7.26 ppm) of the solvent $\mathrm{CDCl}_{3}$ and/or to TMS; the ${ }^{13} \mathrm{C}$ NMR spectra are referenced with respect to the middle peak of $\mathrm{CDCl}_{3}$ solvent $(77.0 \mathrm{ppm})$. Mass spectra were run employing a HewlettPackard Model 5970 mass selective detector (EI, $70 \mathrm{eV}$ ) connected to a Model 5890 gas chromatograph, a Finnigan 311 A, and/or a Finnigan MAT CH 5 DF (EI, 70 eV) instrument. The FT-IR spectra were recorded on a Perkin-Elmer Model 1710 instrument, interfaced with a Model 7300 data station. The GLC analyses were performed on a PerkinElmer Model 8420 or 3800 chromatograph, equipped with an Epson Model FX 850 data station, on a SE 30 or OV $101,30 \mathrm{~m} \times 0.25 \mu \mathrm{m}$ i.d., capillary column. HPLC analyses were performed on a Hewlett-Packard Model 1050 instrument (Model 35900 absorption detector) or on a PerkinElmer Model 3B (Model LC-85B absorption detector), using a Partisil, $250 \mathrm{~mm} \times 4.6 \mathrm{~mm}$ i.d. column (isocratic THF $/ n$-heptane $50: 50,1 \mathrm{~mL} /$ min). Semipreparative HPLC separations were carried out employing a Partisil M9 (Whatman), $25 \mathrm{~cm} \times 10 \mathrm{~mm}$ i.d. column, or a C18 RP, $250 \mathrm{~mm} \times 23.5 \mathrm{~mm}$ i.d. column. In most of the cases, medium pressure column liquid chromatography (MPLC) was carried out using silica gel (Merck LiChroprep Si 60, 25-60 $\mu \mathrm{m}$ ), and TLC performed on precoated silica gel plates (Kieselgel 60, Merck F 254). Other equipment and methods employed have been described previously. 4a,5e,18

Materials. All solvents, starting materials, and compounds used as reference standards in product analyses were of the highest purity commercially available; further purification, whenever appropriate, was achieved by following conventional methods. Purified methylene chloride, acetone, and 1,1,1-trifluoro-2-propanone (TFP) (bp $22^{\circ} \mathrm{C}$ ) solvents were stored over $5 \AA$ molecular sieves at $2-5{ }^{\circ} \mathrm{C}$, routinely redistilled, and flushed with dry $\mathrm{N}_{2}$ prior to use. Curox triple salt $2 \mathrm{KHSO}_{5} \cdot \mathrm{KHSO}_{4} \cdot \mathrm{K}_{2}-$ $\mathrm{SO}_{4}$ (a gift by Peroxid-Chemie GmbH, Munich, Germany) was our source of potassium peroxymonosulfate; it was used as received for the synthesis of dioxiranes 1a and $1 \mathrm{~b}$.

Solutions of $0.08-0.16 \mathrm{M}$ dimethyldioxirane (1a) $2 \mathrm{a}, \mathrm{b}, 18$ in acetone and of 0.8-1.0 M methyl(trifluoromethyl)dioxirane (1b) ${ }^{2 c, 4 a}$ in TFP were obtained by adopting procedures, equipment, and precautions which have been described in detail. The synthesis and spectral characteristics of substrates $9 H, 10 H-4 b, 9 \mathrm{a}-([1,2]$ benzenomethano)indeno[1,2-a]indene (Triptindan) (2), ${ }^{11} 4 \mathrm{~b} \alpha, 8 \mathrm{~b} \beta, 13,14$-tetrahydrodiindeno[1,2-a:2', $\left.1^{\prime}-b\right]$ indene $\left(1,1^{\prime}\right.$-(o-phenylene)-2,2'-spirobiindan) (3), 13a,14 $12 \mathrm{~d}$-methyl-4b $\alpha, 8 \mathrm{~b} \alpha$,$12 \mathrm{~b} \alpha, 12 \mathrm{~d} \alpha$-tetrahydrodibenzo[ $2,3: 4,5]$ pentaleno[ $[1,6-a b]$ indene $(10-$ methyltribenzoquinacene) (4), $13 \mathrm{a}, 15$ and $4 \mathrm{~b} \alpha, 8 \mathrm{~b} \beta, 12 \mathrm{~b} \alpha, 16 \mathrm{~b} \beta$ tetrahydrodibenzo $[a f]$ dibenzo[ $[2,3 ; 4,5]$ pentaleno[1,6-cd] pentalene (fenestrindan) $(5)^{136,14}$ have been reported.

Oxidations with Dimethyldioxirane (1a). General Procedure. The oxidations were carried out at the conditions shown in eqs 1 and 3 and in Scheme 1. An aliquot (usually from $30-40 \mathrm{~mL}$ ) of cold solution of dimethyldioxirane (1a) (standardized by iodometry2a,b or upon reaction with triphenyl phosphine ${ }^{18}$ ) was mixed with solutions of the substrate
$(0.25-1.00 \mathrm{mmol})$ in acetone $(3.0 \mathrm{~mL})$, and the reaction mixtures kept in the dark at room temperature for 4-5 days; the progress of the oxidation was monitored by TLC and/or MS. After removal of the volatile components in vacuo, the residue was usually subjected to MPLC (eluent $\mathrm{CHCl}_{3}$ or $\mathrm{CH}_{2} \mathrm{Cl}_{2}$ ); the products thus isolated were further purified upon recrystallization (whenever appropriate), and identified as reported below.

Oxidations with Methyl(trifluoromethyl)dioxirane (1b). General Procedure. The oxidations were performed at the conditions given in eqs 2 and 4 and in Schemes 1 and 2. An aliquot (usually from 3-4 mL) of cold standardized 4 solution of methyl(trifluoromethyl)dioxirane (1b) in 1,1,1-trifluoropropanone (TFP) was added to a stirred solution of the substrate $(0.26-1.04 \mathrm{mmol})$ in $\mathrm{CH}_{2} \mathrm{Cl}_{2}(5-7 \mathrm{~mL})$, kept at the given temperature $\left(-20\right.$ to $\left.0^{\circ} \mathrm{C}\right)$; in the oxyfunctionalization of fenestrindan (5), tert-butyl alcohol (ca. $20 \% \mathrm{v} / \mathrm{v}$ ) was employed as a cosolvent in order to improve the solubility of intermediate oxidation products. The progress of the reactions was monitored by GC, GC/MS, or HPLC. At the end of the reaction, removal of the volatile components in vacuo gave solid residues which could be analyzed either directly or after conversion of the alcohol products into the corresponding acetates $\left(\mathrm{Ac}_{2} \mathrm{O} / \mathrm{py}\right)$.

Oxidation of Triptindan (2). (A) With 1a. In the reaction of 2 (100 $\mathrm{mg}, 340 \mu \mathrm{mol}$ ), MS analysis of the mixture after 2 days showed the presence of all three possible ketones 6-811 and, in lower amounts, of the corresponding ketoles. MPLC separation gave starting the material ( 30 $\mathrm{mg}$ ) and 9-triptindanone 6 ( $27 \mathrm{mg}, 88 \mu \mathrm{mol}$, yield $37 \%$ based on substrate reacted): after recrystallization (MeOH), $\mathrm{mp} 185-186^{\circ} \mathrm{C}$ [lit. ${ }^{11} \mathrm{mp} 183$ ${ }^{\circ} \mathrm{C}$. The spectroscopic properties of 6 were identical to those of the same material prepared by independent synthesis. ${ }^{11}$

(B) With 1b. The dioxirane solution was added slowly to the substrate (76 mg, $260 \mu \mathrm{mol}$ ) during $20 \mathrm{~min}$; GLCand/or GC/MS analysis revealed that the starting material was completely consumed after ca. $40 \mathrm{~min}$. Removal of the solvent in vacuo afforded an ca, 8:2 mixture of 6 and 7 (78 mg, overall yield ca. 95\%). GC/MS monitoring during the reaction also revealed the presence of 9,10-triptindandiol (9) [MS m/z (ri) 308 $\left(100,\left[\mathrm{M}-\mathrm{H}_{2} \mathrm{O}\right]^{+}\right), 307(14), 280(29), 279(85), 278$ (33), 277 (39), $276(42), 265(24), 263(17), 253(13), 252$ (23), 207 (17), 139 (12), 138 (24), 131 (14), 126 (17), etc.]; this intermediate was found to decay into diketone 7 as the reaction proceeds.

Oxidation of 1,1'-(a-Phenylene)-2,2'-spirobindan (3). (A) With 12 . Upon oxidation of $3(294 \mathrm{mg}, 1.00 \mathrm{mmol})$, MPLC of the yellow residue (250 mg) gave recovered starting material (108 $\mathrm{mg}$ ), monoketone 10 (54 $\mathrm{mg}, 0.18 \mathrm{mmol})$, and monoalcohol $11(32 \mathrm{mg}, 0.10 \mathrm{mmol})$. The yield of products 10 and 11 was $28 \%$ and $16 \%$, respectively, based on substrate reacted. 13-0xo-4b $\alpha, 8 b \beta, 13,14$-tetrahydrodiindeno $\left[1,2-\approx: 2^{\prime}, 1^{\prime}\right.$ - $\left.b\right]$ indene (10): colorless crystals (MeOH), mp $180-182^{\circ} \mathrm{C} ; R_{f} 0.45\left(\mathrm{CHCl}_{3}\right)$; IR (KBr) 3070, 3020, 2950, 2900, 2830, $1705(\mathrm{C}=\mathrm{O}), 1605,795,785,750$, $745,710 \mathrm{~cm}^{-1} ;{ }^{1} \mathrm{H}$ NMR (300 MHz): 87.79 and 7.76 (two d, overlapped, $\left.{ }^{3} J=8.0 \mathrm{~Hz}, 2 \mathrm{H}\right), 7.67\left(\mathrm{t},{ }^{3} J=7.8 \mathrm{~Hz}, 1 \mathrm{H}\right), 7.40-7.47(\mathrm{~m}, 4 \mathrm{H})$, 7.18-7.27 (m, $5 \mathrm{H}), 4.99\left(\mathrm{~s}, 1 \mathrm{H}, \mathrm{CHAr}_{2}\right), 4.73\left(\mathrm{~s}, 1 \mathrm{H}, \mathrm{CHAr}_{2}\right), \mathrm{AB}$ $\left(\delta_{\mathrm{A}} 3.31, \delta_{\mathrm{B}} 3.66, J_{\mathrm{AB}}=-16.5 \mathrm{~Hz}, 2 \mathrm{H}, \mathrm{CH}_{2}\right) ;{ }^{13} \mathrm{C} \mathrm{NMR}(75 \mathrm{MHz}) \delta$ $209.2(\mathrm{C}=0), 156.2(\mathrm{q}), 144.0$ (q), 143.49 (q), 142.49 (q), $141.1(\mathrm{q})$, $135.53(\mathrm{t}), 135.48(\mathrm{q}), 128.1(\mathrm{t}), 127.6(\mathrm{t}), 127.3(\mathrm{t}), 127.2(\mathrm{t}), 125.6(\mathrm{t})$, $124.7(\mathrm{t}), 124.4(\mathrm{t}), 124.1(\mathrm{t}), 66.5(\mathrm{q}, \mathrm{C}-13 \mathrm{~b}), 60.1(\mathrm{t}), 59.1(\mathrm{t}), 43.0$ (s); MS m/z (ri) 308 (100, $\mathrm{M}^{+}$), 280 (10), 279 (22), 278 (12), 277 (13), $276(17), 203$ (13), $202(26), 178$ (9), 165 (9), 91 (11); HRMS caicd for $\mathrm{C}_{23} \mathrm{H}_{16} \mathrm{O} 308.1201$, found 308.1200 . $4 \mathrm{~b} \alpha-\mathrm{Hydroxy}-4 \mathrm{~b} \alpha, 8 \mathrm{~b} \beta, 13,14$ tetrahydrodiindeno[1,2-a:2',1'-b]indene (11): colorless crystals (MeOH/ $n$-pentane), mp $105^{\circ} \mathrm{C}$; ${ }^{1} \mathrm{H}$ NMR $(300 \mathrm{MHz}) \delta 7.60\left(\mathrm{~d},{ }^{3} \mathrm{~J}=6.7 \mathrm{~Hz}\right.$, $1 \mathrm{H}), 7.53(\mathrm{~m}, 1 \mathrm{H}), 7.40(\mathrm{~m}, 1 \mathrm{H}), 7.18-7.35(\mathrm{~m}, 9 \mathrm{H}), 4.30(\mathrm{~s}, 1 \mathrm{H}$, $\mathrm{CHAr} 2), \mathrm{AB}\left(\delta_{\mathrm{A}} 3.00, \delta_{\mathrm{B}} 3.60, J_{\mathrm{AB}}=-16.7 \mathrm{~Hz}, 2 \mathrm{H}, \mathrm{CH}\right), \mathrm{AB}\left(\delta_{\mathrm{A}} 3.27\right.$, $\left.\delta_{\mathrm{B}} 3.31, J_{\mathrm{AB}}=-16.5 \mathrm{~Hz}, 2 \mathrm{H}, \mathrm{CH}_{2}\right), 2.06(\mathrm{~s}, 1 \mathrm{H}, \mathrm{OH}) ; \mathrm{MS} \mathrm{m} / \mathrm{z}$ (ri) 310 $\left(0.4, \mathrm{M}^{+}\right), 292\left(100,\left[\mathrm{M}-\mathrm{H}_{2} \mathrm{O}\right]^{+}\right), 291(39), 290(10), 289$ (11), 276 (5), 265 (5), 219 (3), 215 (7), 165 (4), 91 (4); HRMS caled for $\mathrm{C}_{23} \mathrm{H}_{18} \mathrm{O}$ 310.1358 , found 310.1357 .

(B) With 1b. After the reaction of 3 (305 $\mathrm{mg}, 1.04 \mathrm{mmol})$ had been carried out to $\geq 40 \%$ substrate conversion (GLC), removal of solvent and treatment of the residue with $\mathrm{Ac}_{2} \mathrm{O} / \mathrm{py}$ allowed GLC (and GC/MS) analysis of the product mixture, constituted by ketone 10, acetate 11a, and acetate 12a (cf. eq 2). The yield of products 10, 11a, and 12a was estimated as 39,38 , and $21 \%$, respectively, based on substrate reacted. Column chromatography (silica gel, $\mathrm{Et}_{2} \mathrm{O}$ /petroleum ether, 10:90) was performed to isolate the mixture of acetates $11 \mathrm{a}$ and $12 \mathrm{a}(92 \mathrm{mg}, 0.26$ mmol, $60 \%$ yield total based on substrate reacted). From this, the individual acetates could be separated by semipreparative HPLC (isocratic $\mathrm{CHCl}_{3} / n$-heptane $\left.60: 40,2.5 \mathrm{~mL} / \mathrm{min}\right)$. $4 \mathrm{~b} \alpha$-Acetoxy- $4 \mathrm{~b} \alpha, 8 \mathrm{~b} \beta, 13,14$ tetrahydrodiindeno $\left[1,2-22^{\prime}, 1^{\prime}-b\right]$ indene (11a): pale yellow solid, mp 168$171^{\circ} \mathrm{C}$; ${ }^{1} \mathrm{H}$ NMR (200 MHz) $\delta 7.75\left(\mathrm{~d},{ }^{3} \mathrm{~J}=7.4 \mathrm{~Hz}, 1 \mathrm{H}\right), 7.51\left(\mathrm{~d},{ }^{3} \mathrm{~J}\right.$ 
$=7 \mathrm{~Hz}, 1 \mathrm{H}), 7.43\left(\mathrm{~d},{ }^{3} \mathrm{~J}=7 \mathrm{~Hz}, 1 \mathrm{H}\right), 7.25-7.55($ complex $\mathrm{m}, 9 \mathrm{H})$, $4.26(\mathrm{~s}, 1 \mathrm{H}, \mathrm{CHAr} 2), \mathrm{AB}\left(\delta_{\mathrm{A}} 3.06, \delta_{\mathrm{B}} 3.60, J_{\mathrm{AB}}=-16.8 \mathrm{~Hz}, 2 \mathrm{H}, \mathrm{CH}_{2}\right)$, $\mathrm{AB}$ (centered at $\left.\delta 3.43,2 \mathrm{H}, \mathrm{CH}_{2}\right), 2.10\left(\mathrm{~s}, 3 \mathrm{H}, \mathrm{CH}_{3} \mathrm{CO}\right.$ ); $\mathrm{MS} m / z$ (ri) 294 (4), $293\left(28,\left[\mathrm{M}-\mathrm{CH}_{3} \mathrm{CO}_{2}\right]^{+}\right), 292\left(100,\left[\mathrm{M}-\mathrm{CH}_{3} \mathrm{CO}_{2} \mathrm{H}\right]^{+}\right), 291$ (47), $290(10), 289$ (15), $276(10), 215(8), 145(5), 138(5), 91(3), 43$ (6). $13 \beta$-Acetoxy-4b $\alpha, 8 \mathrm{~b} \beta, 13,14$ tetrahydrodiindeac $\left[1,2-\alpha 2^{\prime}, 1^{\prime}-b\right]^{\prime}$ indene (12a): solid (contaminated by 11a), mp $146-151^{\circ} \mathrm{C}$; ${ }^{1} \mathrm{H}$ NMR $(200$ $\mathrm{MHz}$ ) $\delta$ 7.1-7.5 (complex m, $12 \mathrm{H}$ ), 6.22 (s, $1 \mathrm{H}, \mathrm{CHOAc}), 4.63$ (s, 1 $\left.\mathrm{H}, \mathrm{CHAr}_{2}\right), 4.54\left(\mathrm{~s}, 1 \mathrm{H}, \mathrm{CHAr}\right.$ ), $2.90\left(\mathrm{br} \mathrm{s}, 2 \mathrm{H}, \mathrm{CH}_{2}\right), 2.09(\mathrm{~s}, 3 \mathrm{H}$, $\mathrm{CH}_{3} \mathrm{CO}$ ); $\mathrm{MS} m / z$ (ri) 294 (4), $293\left(24,\left[\mathrm{M}-\mathrm{CH}_{3} \mathrm{CO}_{2}\right]^{+}\right), 292(100$, $\left.\left[\mathrm{M}-\mathrm{CH}_{3} \mathrm{CO}_{2} \mathrm{H}\right]^{+}\right), 291(45), 290(10), 289(15), 276(10), 215(8), 145$ (5), $138(5), 91$ (3), 43 (6).

13a-Hydroxy-4b $\alpha, 8 b \beta, 13,14$-tetrahydrodilindeno $\left[1,2-a: 2^{\prime}, 1^{\prime}-b\right]$ indene (12'). This isomer of 11 was obtained upon reduction of $10(42 \mathrm{mg}, 14$ $\mu \mathrm{mol})$ with $\mathrm{LiAlH}_{4}(20 \mathrm{mg}, 500 \mu \mathrm{mol})$ in dry $\mathrm{Et}_{2} \mathrm{O}(10 \mathrm{~mL})$. Usual workup gave $12(36 \mathrm{mg}, 85 \%)$ as a colorless powder, $\mathrm{mp} 164-165^{\circ} \mathrm{C}$; 'H NMR (300 MHz) 8 7.15-7.45 (m, $12 \mathrm{H}), 5.30(\mathrm{~s}, 1 \mathrm{H}, \mathrm{CHOH}), 4.93$ (s, $1 \mathrm{H}, \mathrm{CHAr}, \mathrm{H}-4 \mathrm{~b}), 4.44$ (s, $1 \mathrm{H}, \mathrm{CHAr} 2,8 \mathrm{~b}-\mathrm{H}), 3.32\left(\mathrm{~s}, 2 \mathrm{H}, \mathrm{CH}_{2}\right)$, 1.85 (very br s, $1 \mathrm{H}, \mathrm{OH}$ ) (the stereochemistry of 12 and the signal assignments were based on its ${ }^{1} \mathrm{H}-{ }^{1} \mathrm{H}$ NOESY spectrum, showing distinct cross peaks for the resonance at $\delta 3.32$ with those at $\delta 5.30$ and $\delta 4.44)$; MS m/z (ri) $310\left(0.2, \mathrm{M}^{+}\right), 292\left(100,\left[\mathrm{M}-\mathrm{H}_{2} \mathrm{O}\right]^{+}\right), 291(36), 290(9)$, 289 (14), $276(7), 265$ (4), $263(2), 215(6), 203(5), 202(6), 165$ (3), $146(5), 91(3)$.

Oxidation of 10-Methyltribenzoquinacene (4). (A) With 1a. Treatment of $4(100 \mathrm{mg}, 340 \mu \mathrm{mol})$ with excess dioxirane yielded, after solvent removal, a light brown residue; MPLC $\left(\mathrm{CH}_{2} \mathrm{Cl}_{2}\right)$ of the latter gave the starting material $(5 \mathrm{mg})$ and monoalcohol $13(10 \mathrm{mg}, 32 \mathrm{mmol}$, yield $10 \%$ ). Elution of the column with $\mathrm{MeOH}$ furnished sizable amounts of diol 14 and triol 15 in mixture (GC/MS), which could not be separated. 19 4b-Hydroxy-12d-methyl-4b $\alpha, 8 \mathrm{~b} \alpha, 12 \mathrm{~b} \alpha, 12 \mathrm{~d} \alpha$-tetrahydrodibenzo[2,3:4,5]pentaleno[1,6-ab]indene (13): noncrystalline solid, $\mathrm{mp} 235^{\circ} \mathrm{C} ;{ }^{196} \boldsymbol{R}_{f} 0.31$ $\left(\mathrm{CHCl}_{3}\right) ;{ }^{1} \mathrm{H}$ NMR (300 MHz) 8 7.61-7.66 (m, $\left.2 \mathrm{H}\right), 7.39-7.45(\mathrm{~m}, 4$ $\mathrm{H}), 7.24-7.28(\mathrm{~m}, 4 \mathrm{H}), 7.19-7.22(\mathrm{~m}, 2 \mathrm{H}), 4.52(\mathrm{~s}, 2 \mathrm{H}, \mathrm{CHAr} 2), 2.36$ (br s, $1 \mathrm{H}, \mathrm{OH}), 1.61\left(\mathrm{~s}, 3 \mathrm{H}, \mathrm{CH}_{3}\right) ; \mathrm{MS} \mathrm{m} / \mathrm{z}$ (ri) $310\left(100, \mathrm{M}^{+}\right), 295$ $\left(41,\left[\mathrm{M}-\mathrm{CH}_{3}\right]^{+}\right), 293\left(36,[\mathrm{M}-\mathrm{OH}]^{+}\right), 267(8), 265(10), 217(7)$, 215 (6), 194 (24), 165 (3), 132 (3), 105 (2), 91 (2); HRMS calcd for $\mathrm{C}_{23} \mathrm{H}_{18} \mathrm{O} 310.1358$, found 310.1357 . Other spectral characteristics were in agreement with reported data. $19 \mathrm{~b}$

(B) With 1b. After the reaction of $4(172 \mathrm{mg}, 585 \mu \mathrm{mol})$ had been carried out to ca. $35 \%$ substrate conversion (GLC), removal of solvent and treatment of the residue with $\mathrm{Ac}_{2} \mathrm{O} / \mathrm{py}$ allowed GLC (and GC/MS) analysis of the reaction mixture; this showed monoacetate 13a as the only product. Isolation of the latter $(73 \mathrm{mg}, 205 \mu \mathrm{mol})$ was achieved by column chromatography (silica gel, $\mathrm{Et}_{2} \mathrm{O} / n$-pentane, 10:90). 4b-Acetoxy-12dmethyl-4b $\alpha, 8 \mathrm{~b} \alpha, 12 \mathrm{~b} \alpha, 12 \mathrm{~d} \alpha$-tetrahydrodibenzo[ $2,3: 4,5]$ pentaleno[1,6-ab] indene (13a): pale yellow solid, mp 166-169 ${ }^{\circ} \mathrm{C} ;{ }^{1} \mathrm{H}$ NMR (200 MHz) o 7.4-7.55 (complex m, $6 \mathrm{H}$ ), 7.2-7.3 (complex m, $6 \mathrm{H}$ ), 4.62 (s, $2 \mathrm{H}$, $\left.\mathrm{CHAr}_{2}\right), 2.14\left(\mathrm{~s}, 3 \mathrm{H}, \mathrm{CH}_{3} \mathrm{CO}\right), 1.66\left(\mathrm{~s}, 3 \mathrm{H}, \mathrm{CH}_{3}\right) ; \mathrm{MS} \mathrm{m} / \mathrm{z}$ (ri) 352 $\left(22, \mathrm{M}^{+}\right), 311(15), 310\left(60,\left[\mathrm{M}-\mathrm{CH}_{2} \mathrm{CO}\right]^{+}\right), 309(6), 295(8), 294(28)$, $293\left(100,[\mathrm{M}-\mathrm{AcO}]^{+}\right), 291(8), 289(8), 279(5), 278$ (17), $276(18)$, 266 (7), 265 (19), 263 (9), 252 (7), 215 (24), 202 (6), 139 (6), 138 (9), $43(15)$.
Oxidation of Fenestrindan (5). (A) With 1a. In the reaction of 5 (90 $\mathrm{mg}, 250 \mu \mathrm{mol}$, MS analysis of the product mixture showed the presence of tetrahydroxyfenestrindan $18\left(m / z \quad 432,[M]^{+}\right)$as the a major component, along with the triol $\left(m / z=398,\left[\mathrm{M}-\mathrm{H}_{2} \mathrm{O}\right]^{+}\right)$and diol(s) $\left(m / z=382,\left[\mathrm{M}-\mathrm{H}_{2} \mathrm{O}\right]^{+}\right)$. Column chromatography (silica gel, $\mathrm{CH}_{2-}$ $\mathrm{Cl}_{2}$ ) furnished pure 18, albeit in low yield. $4 b, 8 b, 12 b, 16 b-T e t r a h y d r o x y$ 4h $\alpha, 8 \mathrm{~b} \beta, 12 \mathrm{~b} \alpha, 16 \mathrm{~b} \beta$-tetrahydrodibenzo[ $\alpha, f]$ dibenzo $[2,3 ; 4,5]$ pentaleno[ $[1,6-$ cdjpentalene (18): $\mathrm{mp} 305^{\circ} \mathrm{C}$; ${ }^{1} \mathrm{H}$ NMR (300 MHz, acetone- $\left.d_{6}\right) \delta 7.66$ and 7.38, $\mathrm{AA}^{\prime} \mathrm{BB}^{\prime}$ system, $5.83(4 \mathrm{H}, \mathrm{OH})$; $\mathrm{MS} m / z$ (ri) $432\left(12, \mathrm{M}^{+}\right)$, $414\left(15,\left[\mathrm{M}-\mathrm{H}_{2} \mathrm{O}\right]^{++}\right), 396\left(100,\left[\mathrm{M}-2 \mathrm{H}_{2} \mathrm{O}\right]^{+}\right), 368(24), 352(12)$, 339 (43). Other spectral characteristics were in agreement with reported data. ${ }^{19,22}$

(B) With 1b. Treatment of 5 ( $315 \mathrm{mg}, 858 \mu \mathrm{mol})$ with $1 \mathrm{~b}$ (molar ratio 1:1.5) in $\mathrm{CH}_{2} \mathrm{Cl}_{2} / t-\mathrm{BuOH} / \mathrm{TFP}$ solution $(9: 1: 1, \mathrm{v} / \mathrm{v})$ led to a $56 \%$ conversion of the starting material after $25 \mathrm{~min}$ at $-10^{\circ} \mathrm{C}$ (HPLC monitoring). Removal of solvent in vacuo, treatment with $\mathrm{Ac}_{2} \mathrm{O} / \mathrm{py}$, and usual workup followed by column chromatography (silica gel, $\mathrm{CHCl}_{3} /$ n-pentane 70:20) furnished monoacetate $17 \mathrm{a}$ (198 $\mathrm{mg}, 464 \mathrm{mmol},>96 \%$ yield based on substrate reacted) as the only reaction product (separated from $t$-BuOAc resulting from acetylation of residual $t$-BuOH cosolvent). 4b-Acetoxy-4b $\alpha, 8 b \beta, 12 \mathrm{~b} \alpha, 16 \mathrm{~b} \beta$-tetrahydrodibenzo[ $[a, /$ dibenzo $[2,3 ; 4,5]$ pentaleno[1,6-cdpentalene (17a): pale yellow solid, $\mathrm{mp} 233-235^{\circ} \mathrm{C}$ dec; FT-IR (KBr) 3069, 3029, 2928, 2856, $1742(\mathrm{C}=0), 1367,1237 \mathrm{~cm}^{-1}$, etc.; ${ }^{1} \mathrm{H}$ NMR $(200 \mathrm{MHz}) \delta$ 7.87-7.92 (m, $\left.2 \mathrm{H}\right)$, 7.45-7.6 (m, $\left.6 \mathrm{H}\right)$, 7.2-7.45 (complex m, 8 H), 5.14 (s, $1 \mathrm{H}, \mathrm{CHAr}$ ), $4.85(\mathrm{~s}, 2 \mathrm{H}, \mathrm{CHAr})_{2}$ ), $1.84\left(\mathrm{~s}, 3 \mathrm{H}, \mathrm{CH}{ }_{3} \mathrm{CO}\right) ;\left\{{ }^{1} \mathrm{H}\right\}^{13} \mathrm{C}$ NMR $(50 \mathrm{MHz}) \delta 168.4\left(\mathrm{CH}_{3} \mathrm{CO}\right)$, $144.0,142.5,141.6,128.8,127.1,127.0,125.4,123.7,123.6,123.3,98.8$ (C-OAc), 75.2 (C-16d), 62.3 (CHAr $)$, $55.7\left(\mathrm{CHAr}_{2}\right), 21.3\left(\mathrm{CH}_{3}\right)$.

Treatment of 5 (108 mg, $294 \mu \mathrm{mol})$ with excess $1 \mathrm{~b}$ (molar ratio 1:10) in $\mathrm{CH}_{2} \mathrm{Cl}_{2} / t-\mathrm{BuOH} / \mathrm{TFP}$ solution $(5: 1: 4, v / v)$ led to $97 \%$ conversion of the starting material after $25 \mathrm{~min}$ at $-10^{\circ} \mathrm{C}$ (HPLC monitoring); after solvent removal in vacuo, treatment with $\mathrm{Ac}_{2} \mathrm{O} / \mathrm{py}$ and semipreparative HPLC (isocratic THF $/$-heptane $50: 50, \lambda 254 \mathrm{~nm}, 2.5 \mathrm{~mL} / \mathrm{min}$ ) afforded tetraacetate $18 \mathrm{a}$ ( $96 \mathrm{mg}, 160 \mu \mathrm{mol}$, yield 56\%). Recrystallization $\left(\mathrm{CH}_{2-}\right.$ $\mathrm{Cl}_{2} / n$-pentane) afforded pure $4 \mathrm{~b}, 8 \mathrm{~b}, 12,16 \mathrm{~b}$-Tetraacetoxy- $4 \mathrm{~b} \alpha, 8 \mathrm{~b} \beta, 12 \mathrm{~b} \alpha$,$16 \mathrm{~b} \beta$-tetrahydrodibenzo[ $a, f]$ dibenzo $[2,3 ; 4,5]$ pentaleno $[1,6-c d]$ pentalene (18a): pale yellow solid, mp ca. $187^{\circ} \mathrm{C} \mathrm{dec}$; FT-IR (KBr) 3071,2925 , $2853,1749(\mathrm{C}=0), 1370,1224 \mathrm{~cm}^{-1}$, etc.; ${ }^{1} \mathrm{H}$ NMR $(200 \mathrm{MHz}) \delta 7.25-$ 7.65 (complex m), $1.87\left(\mathrm{~s}, 12 \mathrm{H}, \mathrm{CH}_{3} \mathrm{CO}\right) ;{ }^{13} \mathrm{C}$ NMR ( $\left.50 \mathrm{MHz}\right) \delta 168.8$ $\left(\mathrm{q}, \mathrm{C=}\right.$ ) $, 129.6(\mathrm{t}), 124.1(\mathrm{t}), 78.2(\mathrm{q}, \mathrm{CAr}), 22.5\left(\mathrm{CH}_{3}\right)$.

Acknowledgment. Financial support by the Deutsche Forschungsgemeinschaft (DFG, Bonn, Ku 663-2) and by the Ministry of University, Scientific and Technological Research (MURST 40) of Italy is gratefully acknowledged. Thanks are due to professor John O. Edwards (Brown University) for helpful discussions; C.F. and R.C. are grateful for generous hospitality (summer of 1993) to the Chemistry Department, Brown University (a most gracious host institution). 